\title{
Rock Tale Drilling Prototype : An Innovative Design for Investigation of Rock Properties
}

\author{
Rekha Tomar \\ Academy of Scientific and Innovative Research \\ CSIR-Central Institute of Mining \& Fuel Research \\ Dhanbad, India
}

\author{
Dilip Kumbhakar \\ Longwall Mining Division \\ CSIR-Central Institute of Mining and Fuel Research \\ Dhanbad, India
}

\begin{abstract}
Assessing the physico-mechanical properties of rock is one of the important factors of concern to the engineers in the general field of rock excavation. Different direct and indirect methods are applied to determine the rock properties. This paper deals with the details of a design concept applied to develop a drilling prototype which generates online drilling parameters and can be used to correlate with various rock properties.
\end{abstract}

Keywords - Prototype, microcontroller, Infra red, Hall effect, data logger, signal conditioning, signal convertor.

\section{INTRODUCTION}

In mining industry, the knowledge of physico-mechanical properties of rock types, viz. uniaxial compressive strength, tensile strength, Young's modulus of elasticity, density, Poisson's ratio, etc., is very important for design and stability analysis of different structures, like, pillars, openings and slopes $[14,17]$. These properties are also important for optimizing many mining operations, such as, blasting and mechanical excavation of rocks and minerals.

The physico-mechanical properties of rocks are generally determined in the laboratory according to ASTM/ISRM suggested standard methods [2,6] stipulated for each property. However, these methods are time consuming and expensive. To obtain realistic results of rock properties, it requires carefully prepared rock samples. The standard cores cannot always be extracted from weak, highly fractured, thinly bedded, foliated and/or block-in-matrix rocks. Weak to very weak rocks may deteriorate during coring and fail to yield good quality samples.

Worldwide various studies have been conducted which clearly establishes specific relation between the physico-mechanical properties of different rock types and different drilling indices, like, rate of penetration (ROP), specific energy (SE) and heating rate (HR) are calculated from drilling parameters, such as, penetration, drilling speed, current, voltage, load, temperature etc. $[1,4,7,8,10,11,13]$. Taking cue from the above, an effort has been made to develop an alternative method using the drilling technique to determine different rock properties.

The paper deals with the details of a design concept used to develop a drilling prototype which generates online drilling parameters and can be used to correlate with various rock properties. Such a system is a very useful testing installation from which most of the rock properties can be estimated.

\section{DESIGN CONSIDERATIONS}

The main considerations to design and develop the proposed drilling prototype are to formulate design criteria; make necessary sensory arrangements in a drilling machine; measure the drilling parameters; integrate the modular units, mechanical units with proper interfacing; and provide appropriate control and data logging mechanism. The methodology adopted for the design and development of the drilling prototype is given in figure 1 . The proposed system facilitates calculation of rate of penetration, specific energy and heating rate from which different rock properties can be determined.

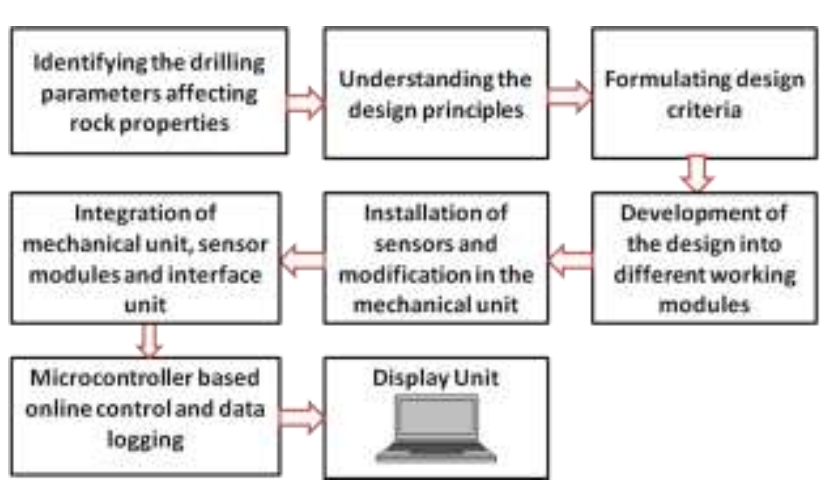

Figure 1. Flow chart showing the methodology adopted for development of the drilling prototype

\subsection{Rate of Penetration}

The rate of penetration, also termed as penetration rate or drill rate, is the speed at which a drill bit breaks the rock under it to deepen the borehole $[5,7,8]$. It is normally measured in meters per hour or meters per minute or meters per second in SI units. It is calculated as:

$R O P=\frac{D}{\Delta t}$

where, $\quad D=$ Depth of drilling, $\mathrm{mm}$ or $\mathrm{m}$ $\Delta t=$ Time duration, sec or min.

\subsection{Specific Energy}

The concept of specific energy ( $S E$ ) was proposed by Teale [16] as a quick means of assessing rock drillability and defined it as the energy required to remove a unit volume of rock.

$S E$ can be measured in $\mathrm{KJ} / \mathrm{m}^{3}$ or $\mathrm{GJ} / \mathrm{m}^{3}$ and can be expressed as follows:

$S E=\frac{F}{A}+\frac{2 \pi N T}{A * R O P}=E_{t}+E_{r}$

where, $\quad F=$ thrust/weight on the bit $(\mathrm{kN})$.

$\mathrm{A}=$ hole section $\left(\mathrm{m}^{2}\right)$.

$\mathrm{N}=$ rotation speed (rps).

$\mathrm{T}=$ rotation torque $(\mathrm{kN} \cdot \mathrm{m})$.

$\mathrm{ROP}=$ rate of penetration $(\mathrm{m} / \mathrm{s})$. 
The first member of the equation, $E_{t}$ represents the contribution of the thrust (thrust component). It is equivalent to the pressure acting over the cross - sectional area of the hole. The second member, $E_{r}$ is the rotary component of energy.

It is evident from equation 2 , that to calculate the specific energy, the drilling parameters, namely, thrust, torque, penetration rate and rotational speed need to be measured [3, $12,15,16]$. The torque in equation 2 can be determined in terms of voltage and current as follows:

$$
\begin{gathered}
T=\frac{P}{2 \pi N} \\
P=\mathrm{V} \times \mathrm{I} \times \cos \emptyset
\end{gathered}
$$

where, $\quad T=$ motor torque, $\mathrm{KNm}$

$P=$ motor power, $\mathrm{KWh}$

$V=$ voltage, volt

$I=$ current, ampere

$\cos \phi=$ power factor of the motor $=0.71$ for the motor under use

Thus equation 2 can be written as

$S E=\frac{F}{A}+\frac{V * I * \cos (\phi)}{A^{*} R O P}$

\subsection{Heating Rate}

Temperature variation occurs at the drill bit due to the heat produced while drilling $[18,19]$. The heating rate $(\mathrm{HR})$, defined as the rate of change in temperature with respect to time, has been used in the design scheme for correlation with rock properties. It can be calculated as:

$H R=\frac{\Delta T}{\Delta t}$

where, $\quad \mathrm{HR}$ is the heating rate, ${ }^{\circ} \mathrm{C} / \mathrm{sec}$

$\Delta \mathrm{T}$ is the change in temperature, ${ }^{\circ} \mathrm{C}$

$\Delta \mathrm{t}$ is the duration of drilling, sec.

The process of drilling invariably increases temperature of either the drill or the job on which it is being operated. The rate of increase in temperature will greatly be influenced by the rock types and their physico-mechanical properties. Hence, this parameter can act as a means to study the rock properties.

\section{DETAILS OF THE PROTOTYPE}

The complete system comprises mainly of three components. The first one consists of the integrated modules of sensors and interfacing units and the data logger unit housed in a CPU enclosure. The second component includes the drill machine with all modifications incorporated to facilitate controlled testing of the samples. The third component comprises of a computer with the requisite software to configure the machine, controlling the operation and logging and retrieval of data.

The drilling prototype is fabricated using a bench type high speed rotary drill machine, array of sensors, signal convertor and conditioning units, microcontroller based operation unit, suitable interface with computer and an application software for on-line configuration, control and data logging [9]. The block diagram of the entire system is shown in figure 2.

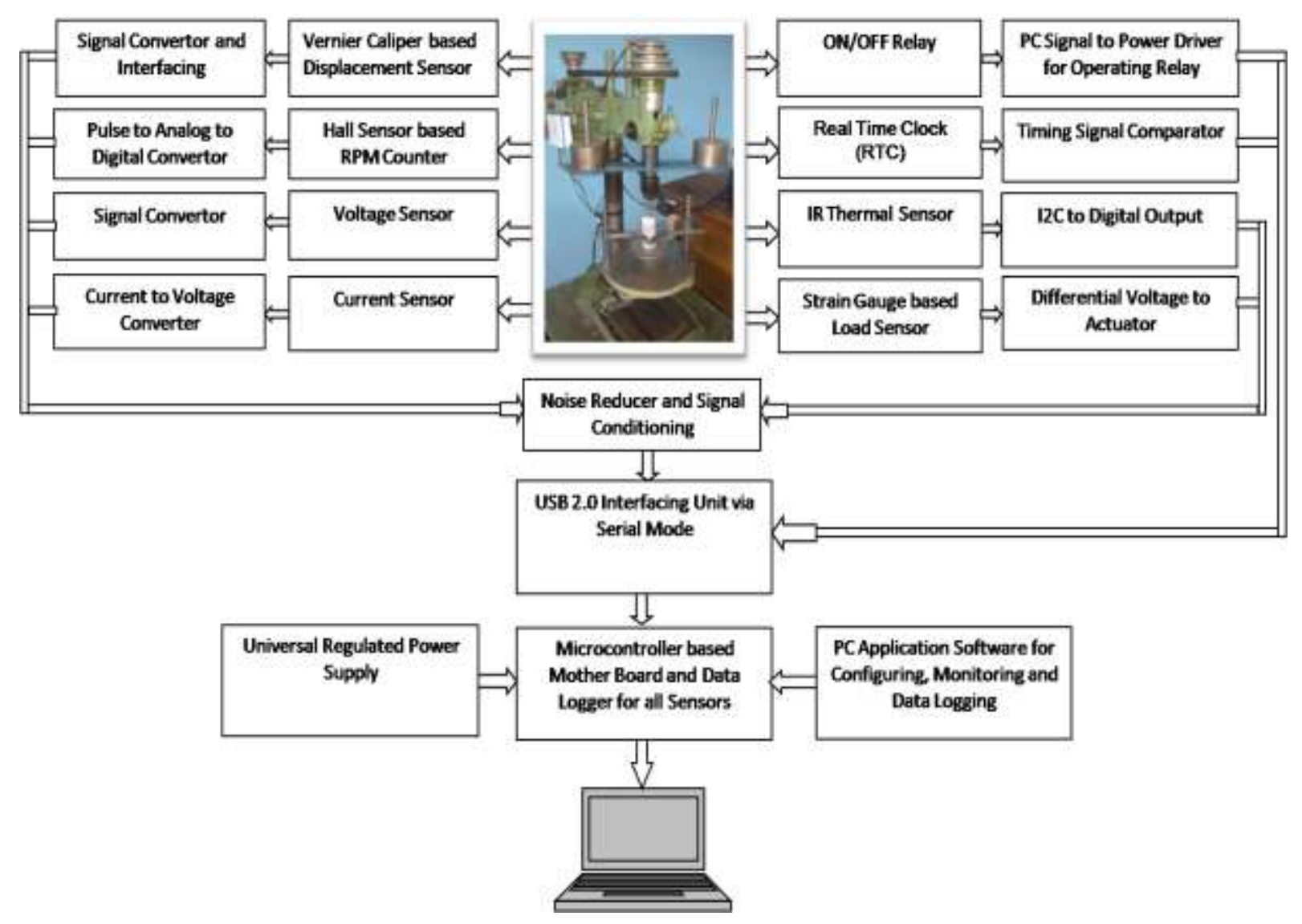

Figure 2: Block Diagram of the Rock Tale Drilling Prototype 


\subsection{Sensor Network}

The system comprises of an array of sensors used for measurement of the drilling parameters.

- Digital vernier caliper has been used to measure the depth of drilling.

- Weight on bit is measured by using a load cell fitted at the base plate.

- Cross-section area is calculated from the bit diameter.

- Rotational speed is measured by the Hall effect sensor based RPM counter.

- $\quad$ ROP is determined as already discussed above in section 2.1 .

- Voltage and current are measured by using voltage or current sensors.

- Temperature is measured by using an infra red thermal sensor.

- Real time clock records the time.

Most of the sensors generate analog signals. To enable the microcontrollers to detect these signals, suitable analog-to-digital convertors are used in the sensor modules. However, the signal generated by the sensors have very low voltage levels. Hence, signal conditioning units are also used in the system to amplify the voltage signals generated before they can be digitized accurately and effectively measured.

\subsection{Mechanical Arrangements}

The laboratory scale experimental setup has been built up from Elliot make bench type high speed rotary drill machine shown in figure 3. Several modifications have been incorporated in the existing drill machines to enable measurements of the desired parameters.

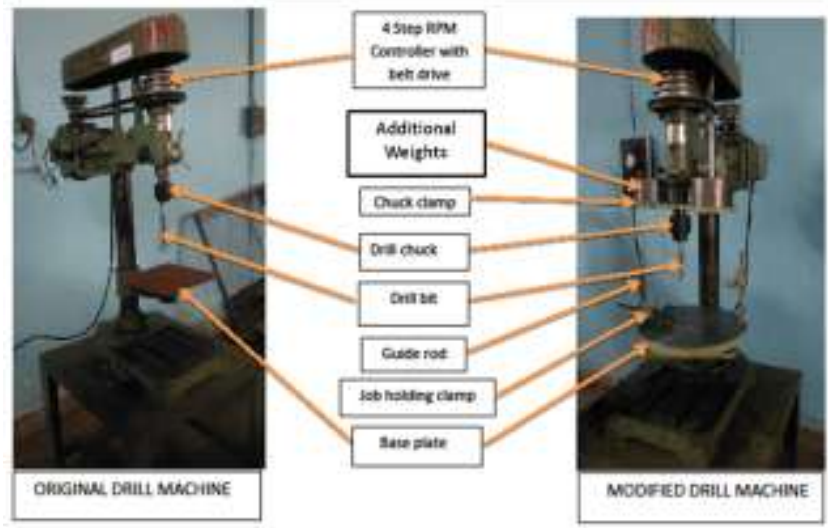

Figure 3: Modifications incorporated in the drill machine

A digital vernier caliper is fixed with the body of the drill machine and the external jaw is connected to the chuck clamp (figure 4) to measure the movement of the clamp when drill penetrates through the sample.

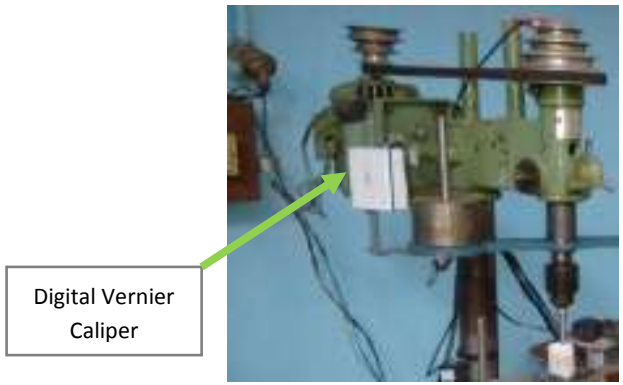

Figure 4: Arrangement showing digital vernier caliper for measurement of penetration
The drill machine has a four step rpm controller using an endless belt. On the top surface of the pulley, the Hall effect rpm sensor is fitted along with the magnetic ring as shown in figure 5.

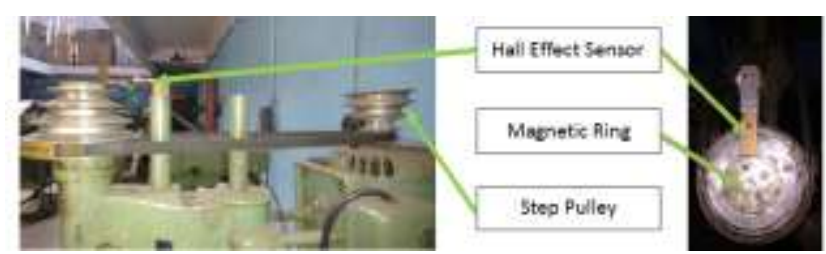

Figure 5: Arrangement showing step rpm controller with Hall sensor

A dumb-bell shaped chuck clamp, shown in figure 6, is fitted in the drill chuck for providing additional weight on its both sides. These weights are used for increasing thrust or weight on the bit.

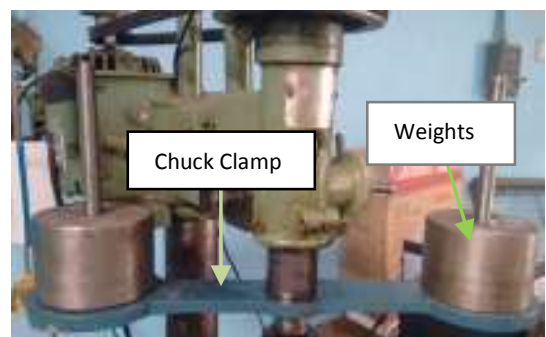

Figure 6: Arrangement showing chuck clamp with provision for additional weights

A guide rod is used for steadying or directing the motion of job holding clamp. A clamp is used in the proposed system to hold the rock samples firmly and only allows free vertical movement. The base plate has been incorporated in the system to place the rock sample over it. It is fitted with the load cell at the bottom to measure the weight of the bit on the sample and the IR sensor for measurement of temperature variation at the bit surface. The arrangement is shown in figure 7.

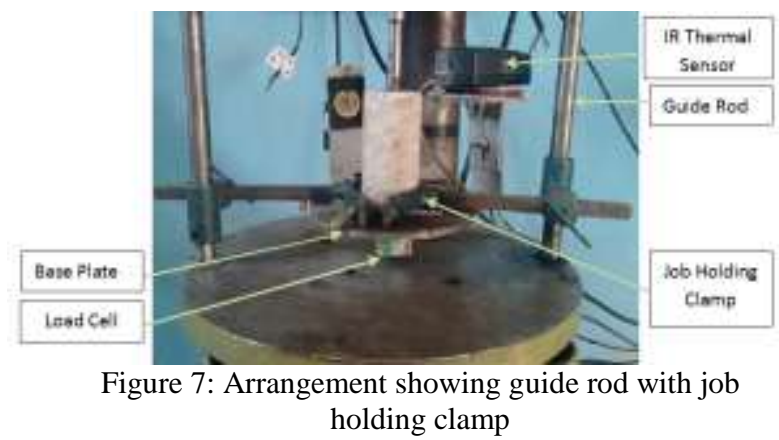

The integrated system comprising of the mechanical unit, sensory arrangements, control unit, interface unit and display unit with software is shown in figure 8 .

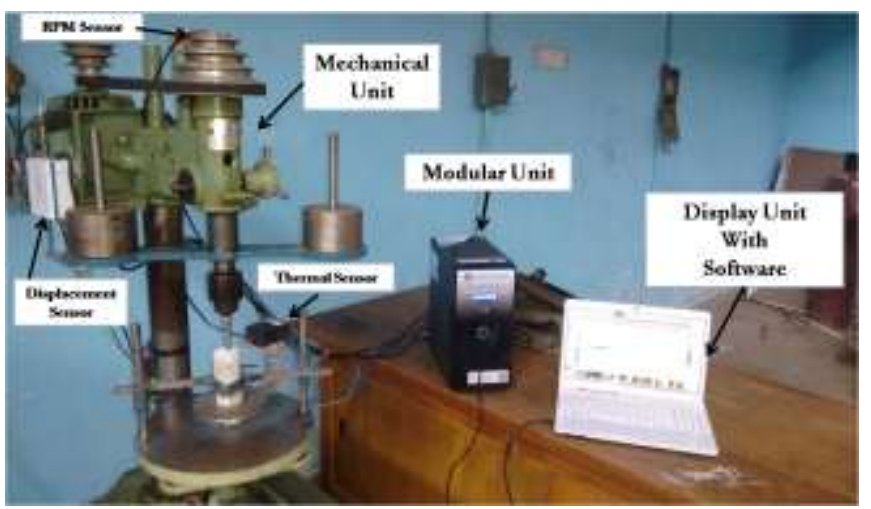

Figure 8: The Integrated Rock-Tale System 


\subsection{Working of the System}

The device is constructed with power feed technology to drill the rock sample up to certain specified depth, programmed through keyboard using the application software. Provision of clockwise and anti-clockwise movement have been made to ensure that the motor moves the drilling machine upward and downward direction while drilling the hole over the rock sample. The facility for calibrating the sensors before start of any test is also provided with the system. The drilling operation is controlled by the microcontroller based operation unit. The data generated during drilling operation were transferred to the computer through an USB interface.

A snap shot of the automatic rock tale drilling data logger and controller is shown in figure 9 .

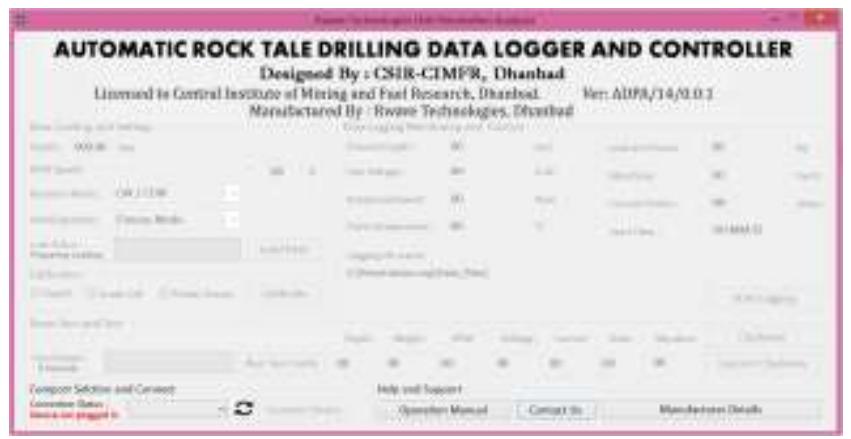

A typical datasheet generated from a drilling test is shown in figure 10.

\begin{tabular}{|c|c|c|c|c|c|c|}
\hline $\begin{array}{c}\text { Time } \\
\text { (HIS:MM:55) }\end{array}$ & $\begin{array}{l}\text { Peortraciaa } \\
\text { (mim) }\end{array}$ & $\begin{array}{l}\text { Lead } \\
\text { (Ke) }\end{array}$ & $\begin{array}{l}\text { Speed } \\
\text { (RTME) }\end{array}$ & $\begin{array}{c}\text { Temperatere } \\
\mathrm{CO}\end{array}$ & $\begin{array}{l}\text { Curmat } \\
\text { (Ange) }\end{array}$ & $\begin{array}{l}\text { Vobage } \\
\text { fValteg }\end{array}$ \\
\hline 1159008 & 0 & 16.49 & 0 & 33.06 & 0.24 & 0 \\
\hline $11-5909$ & 0.02 & 10.59 & 290 & 33.02 & 397 & 190 \\
\hline $1159-10$ & 0.14 & $26 . \pi$ & 280 & 32.96 & 135 & 191 \\
\hline 1152.11 & 0.27 & 16.77 & 210 & 3304 & 382 & 100 \\
\hline 1159.12 & 0.54 & 16.72 & 210 & 32.9 & 3.82 & 191 \\
\hline 1159.13 & 0.74 & 16.57 & 210 & 33.1 & 3.82 & 191 \\
\hline $1159: 24$ & 0.91 & 16.73 & 210 & 31. & 391 & 192 \\
\hline 115015 & 108 & 160 & 210 & 38.1 & 182 & 192 \\
\hline 115928 & 1.26 & $\$ 0.39$ & 210 & 33.1 & 282 & 592 \\
\hline $11-50-17$ & 1.4 & 16.87 & 210 & 3312 & 283 & 192 \\
\hline 1159.18 & 1.61 & 16.84 & 210 & 33.16 & 3.81 & 192 \\
\hline 1159.19 & $1 \pi 7$ & 16.95 & 210 & 33.12 & 3.84 & 193 \\
\hline 1159220 & 191 & 16.98 & 210 & 3312 & 381 & 192 \\
\hline 1159.21 & 2.06 & 27.11 & 280 & 3202 & 131 & 192 \\
\hline 1150.22 & 217 & 17.35 & 210 & 33.1 & 382 & 102 \\
\hline 1159.23 & 2.31 & 17.34 & 210 & 3326 & 3.82 & 193 \\
\hline 1159.24 & 2.45 & 16.99 & 240 & 33.24 & 38 & 191 \\
\hline $1159: 25$ & 255 & 16.93 & 200 & 33.12 & 3.81 & 191 \\
\hline 1159.20 & 205 & 17 & 240 & 32.16 & 2.93 & 192 \\
\hline 1159.27 & 272 & 27.35 & 240 & 33.16 & 3.83 & 193 \\
\hline 1159.28 & 2.8 & 17.31 & 240 & 33.12 & 381 & 191 \\
\hline $11-59.29$ & 289 & 17.19 & 180 & 33.16 & 3.82 & 192 \\
\hline $11-59 \cdot 30$ & 3.08 & 1704 & 180 & 3316 & 3.82 & 291 \\
\hline 115931 & 221 & 17.3 & 250 & 3112 & 2.32 & 592 \\
\hline 1150.32 & 336 & 17.49 & 20 & 31.1 & 4.17 & 191 \\
\hline 1159.13 & 3.6 & 17.36 & $2 \pm 0$ & 33.18 & 42 & 292 \\
\hline $1159: 34$ & 3.83 & 17.03 & 210 & 33.12 & 238 & 192 \\
\hline $1159: 35$ & 602 & 37.95 & 210 & 3106 & 281 & 391 \\
\hline $1150: 16$ & 4.13 & 17.19 & 210 & 33.12 & 279 & 192 \\
\hline 115937 & 4.28 & $17.4 \mathrm{a}$ & 220 & 39.12 & 3.79 & 292 \\
\hline
\end{tabular}

\section{CONClusions}

The rock tale drilling prototype is capable of generating online performance parameters, such as, penetration, drilling speed, current, voltage, load, temperature etc. These parameters can be used to calculate drilling indices, like, rate of penetration, specific energy and heating rate which bear very good relation with different rock properties. Such a system will be a very useful testing installation from which most of the rock properties can be estimated.

\section{ACKNOWLEDGMENTS}

Our sincere thanks to Director, CSIR-Central Institute of Mining \& Fuel Research, Dhanbad for giving permission to publish this paper and guiding us during execution of the project.

\section{REFERENCES}

[1] Adamson W.R. 1984, "Correlation of model excavating machine performance with rock properties and rotary drilling performance data", MSc. Thesis, University of Queensland, p. 124.

[2] ASTM 1986, "Standard test method of unconfined compressive strength of intact rock core specimens", ASTM Publication.

[3] Celada B., Galera J.M., Munoz C. and Tardaguila I. 2009, "The use of the specific drilling energy for rock mass characterization and TBM driving during tunnel construction", ITA-AITES World Tunnel Congress, Budapest, Hungary.

[4] Fish B.G. 1968, "The basic variables in rotary drilling", Mine and Quarry Engineering, 27, pp. 74-81.

[5] Hoseinie S.H., Atael M. and Aghababaie A. 2014, "A lab study of rock properties affecting the penetration rate of pneumatic top hammer drills", Journal of Mining and Environment, vol.5, no.1, 25-34.

[6] ISRM 2007, "The Complete ISRM Suggested Methods for Rock Characterization, Testing and Monitoring: 1974-2006", International Society for Rock Mechanics, Commission on Testing Methods.

[7] Kahraman S., Balci C., Yazici S. and Bilgin N. 2000, "Prediction of the penetration rate of rotary blasthole drilling using a new drillability index", Int. J Rock Mech. \& Min. Sci., 37: 729-43.

[8] Kahraman S. and Bilgin N. 2003, "Drillability Prediction in Rotary Blast Hole Drilling", International Mining Congress and Exhibition of Turkey-IMCET, ISBN 975395-605-3.

[9] Lundberg B. 1982, "Microprocessor simulation of percussive drilling", International Journal of Rock Mechanics and Mining Science, 19: 229-39.

[10] Pandey A.K., Jain A.K. and Singh D. P. 1991, "An investigation into rock drilling", Int. Journal of Surface Mining Reclamation, 5, pp. 139-141.

[11] Paone J., Madson D. and Bruce W. E. 1969, "Drillability studies-laboratory percussive drilling", US Bureau of Mines, RI 7300.

[12] Reddish D.J. and Yasar E. 1996, "A new portable rock strength index test based on specific energy of drilling", Int. J. Rock Mech. Min. Sci., 33(5): pp. 543-548.

[13] Selmer-Olsen R., Blindheim O.T. 1970, "On the drillability of rock by percussive drilling", In: Proceedings of the Second Congress International Society on Rock Mechanics, p. 65-70.

[14] Singh D.P. 1969, "Drillability and physical properties of rocks", Proc. Rock Mechanics Symp., University of Sydney, pp.29-34.

[15] Sinkala T. 1991,"Improving hole quality by automatic control of drilling process: theoretical and field studies". Min Sci Technol 1991; 12:79-88 
[16] Teale R. 1965, "The concept of specific energy in rock drilling", Int J Rock Mech Min Sci, 2: 57-71.

[17] Thuro K. 1997, "Drillability prediction geological influences in hard rock drill and blast tunneling", Geol Rundsch, 86:426-438

[18] Tu, Y. K., Chen, L. W., Ciou, J. S., Hsiao, C. K. and Chen, Y. C. 2013. Finite element simulations of bone temperature rise during bone drilling based on a bone analog, Journal of medical and biological engineering, vol. 33 , no. 3 .

[19] Zhi-jun, W., Yang-sheng Z., Yuan Z. and Chong W. 2009. Research Status Quo and Prospection of Mechanical Characteristics of Rock under High Temperature and High Pressure, Proceedings Earth and Planetary Science, no 1, 2009, pp. 565-570. 